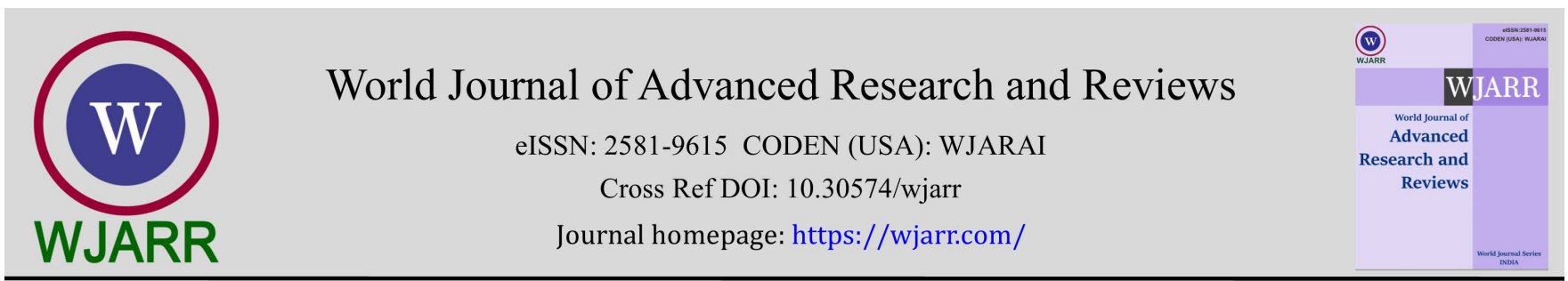

(RESEARCH ARTiClE)

\title{
Human resources for health talent management contribution: A case for health systems strengthening in the public health sector
}

\author{
Bernard Nkala ${ }^{1}{ }^{*}$, Charles Mudimu ${ }^{2}$ and Angelbert Mbengwa Mbengwa 1 , \\ ${ }^{1}$ Health Service Board, Zimbabwe. \\ ${ }^{2}$ Department of Human Resources for Health, Ministry of Health and Child Care, Zimbabwe.
}

World Journal of Advanced Research and Reviews, 2021, 09(02), 192-201

Publication history: Received on 22 January 2021; revised on 18 February 2021; accepted on 20 February 2021

Article DOI: https://doi.org/10.30574/wjarr.2021.9.2.0062

\begin{abstract}
Talent Management is an essential component in transforming health systems if carefully implemented for the public sector especially in low income countries. In Zimbabwe public health sector, talent retention and engagement are viewed as amongst the challenges affecting the realisation of effective performance and productivity from the existing Health workforce. Largely, modern health care systems lack robust strategies to identify and utilize employee talent essential to help attain organisational citizenship. The study reviewed the relevancy and effectiveness of talent management practices in the public health sector using a case study of Parirenyatwa Group of Hospitals, one of the major referral hospitals in Zimbabwe. The study aimed at closing the talent pipe-line gaps as part of the Health Systems Strengthening initiative towards bringing about talent retention and engagement amongst the health workforce in public sector settings. The study assessed the impact of the existing talent management initiatives focusing on variables; recruitment and attraction perspective, compensation and rewarding component, health workforce succession management and implemented performance management system.
\end{abstract}

The study obtained cross sectional data collected through a designed tool following a purposive (non-probability) sampling technique from a sample of $n=200$ existing health management team to assess the perception of implemented talent management approaches. The study further used responses from $n=450$ randomly selected health professionals recruited in the last 3 years prior to the survey to analyse the association between the variables on talent management practices namely (recruitment and selection, compensation and rewarding, succession management and performance management system) and the age of health workforce to employee engagement. The data on recruited cadres was obtained from the existing Hospital Human Resources for Health Recruitment Database. The research revealed that talent management in public health sector currently suffers from theoretical problems since the existing Human Resources for Health literature concentrates on anecdotal information. The human resource practitioners need to come up with more involving workplace activities to demystify the theory that millennials are generally finding it difficult to engage. In addition, the public sector succession planning strategies would need to be in place for the millennials well in time to adequately replace the considerable number of those at retiring stages. The Logistic regression analysis revealed recruitment and attraction perspective, and succession management positively influence health workforce engagement while adherence to implementing performance management system negatively affected employee engagement. Compensation and rewarding practices in a public health set up proved an insignificant variable to health workforce engagement hence study concluded further analysis on the impact on wider target group. The study revealed as the age increases, the health workforce become more engaged and self-motivated to develop their personal talent, thus theory suggests such are 'Baby Boomers' age group that do not need much push and are prepared to perfect their work talent for the benefit of the health system. The role of performance management system must be equally elevated within health system initiatives in order to achieve ultimate health workforce engagement. The study recommended the public health sector to incorporate in its human resources policy, a strategy for managing and utilisation of talent

\footnotetext{
${ }^{*}$ Corresponding author: Dr Bernard Nkala

Health Service Board, Zimbabwe.
}

Copyright (C) 2021 Author(s) retain the copyright of this article. This article is published under the terms of the Creative Commons Attribution Liscense 4.0. 
from the different health workforce generations within the health system. In improving the performance of public health systems, talent management need to be put forward in the health systems strengthening agenda in order to build highly engaged health teams. Talent management practices become essential and if carefully implemented, are likely to help public health systems retain rare skills especially in highly specialised functions. Furthermore, the organisations need to synchronise its strategic plan with the talent management strategy. There must be continuous capacity building of human resources departments to firstly own policies that influence talent management so as to ensure ultimate health workforce engagement.

Keywords: Talent Management; Health Systems Strengthening; Engagement; Public sector

\section{Introduction}

The development of explicit human resources policies is a crucial link in health policies needed both to address the imbalances of the health workforce and to foster implementation of the health services reforms [1] . Talent management is often viewed as one of the health systems strengthening initiative pillars for transformation of health service delivery especially for public sector settings. Researchers have been seized with establishing the relationship between talent management and organizational performance, owing to lack of empirical evidence, which can be largely attributed to the insufficiency of talent management theory [2]. The study targeted on reviewing talent management practices as applicable in the public sector, establishing their contribution on improved workforce performance. Talent management is defined as the methodically organized, strategic process of getting the right talent on board and helping them grow to their optimal capabilities keeping organizational objectives in mind [3]. It is about bringing together the resources required to fulfil a particular vision of an organization. There is however a symbiotic relationship that begins to develop between the organization and the individual in that while the organization is pursuing its objectives, it is also in the process helping the individual to develop.

Prachi Juneja [4], in an article published by the Management Study Guide, emphasises that talent management is more about "managing the ability, competency and power of employees within an organization." This thought contends therefore that while it is important to source talent, the bigger challenge is in the nurturing of that talent to its optimum levels. Talent management is viewed as broad hence is always talked about in all spheres of life where there is competition. Therefore, the term "skills management" is interchangeably preferred in a contextualised sense. The term talent management is a new phenomenon within the developing countries, although the concept of talent management is inherently embedded in their human resources management practices. Talent management is viewed as an element of human resource management strategies, consisting of the execution of interconnected approaches executed to improve workforce engagement and performance through developing measures for attracting, retaining, developing, and retaining individuals with the requisite skills and relevant qualifications to accomplish business targets [5]. Thunnisen et al. [6], defined talent management as "a system that involves a complete and interrelated set of organizational actions such as identifying, selecting, developing and retaining the outstanding workforce, thus refining their capabilities and potential for the strategic positions", which helps workforce to perform and effectively engage [7]. Talent management is further conveyed as a logical perception for attracting, screening, and selecting appropriate talent, promoting engaging and retaining talented workforce, in order to maintain a talent pool $[6,8]$.

Tansley et al [9] considers talent at the short-term level as being associated with satisfying the immediate needs of the organisation. This implies that there is need to have talented individuals at all levels of the organisation. At the longterm level, the organisation considers talent as individuals who demonstrate the ability to progress to senior levels of management. Organizations that invest in their workforce and prioritise human capital needs are more likely to experience increased employee engagement thus maximize their chances of attaining organizational goals and objectives with sustainable performance [10]. Rop [11] claimed, the growth and success of organizations depend on identification of the right employees with the right skills, placed correctly within appropriate timing, where those talented are picked to lead the organization towards its competitive advantage points. Published literature proves that ideally, talented employees form only $3-5 \%$ of the total workforce in an organization [12]. Eventually, effective implementation of talent management practices leads to the development of talented personnel [13], and consequently will lead to improved workforce engagement and sustainable organizational performance. Therefore, there is sufficient ground to hypothesise that effective human resources for health talent management practices trigger increased workforce engagement within a functional public health sector setting.

A sound Human Resources for Health strategy should consist of a methodology for improving its workforce, by means of identifying the recruitment talent pool, developing a competitive compensation plan, setting a robust career management and performance management frameworks, so as to be able to boost organization's competitive advantage 
[14]. Modern health service organizations have begun finding and implementing a talent management strategy within systems strengthening framework in order to match the global market context [15].

In rolling out their talent management system, the ELMO Cloud HR and Payroll [16] contend that "between recruiting the right candidate, on-boarding them, and on to succession planning, there is a lot to manage. Having the right talent management system can help streamline all human resources processes." ELMO [16] thus postulates that using a systematic approach to source, manage and retain talent will help the organisation achieve greater benefits as systems become more streamlined through attention to each of the stages of a talent management system. A robust talent management system would help the organisation with; strategic hiring process; improved on-boarding experience; retaining 'Top Talent'; employee development; improved employee experience and increased employee and manager engagement $[11,17]$. Therefore, in this study, talent management if effectively managed, is believed to stimulate health workforce engagement, hence this supposition influenced data modelling to ascertain the association. Rastgoo [18] and Moghtadaie and Taji [19] in their study on the relationships between talent management practices and organizational performance, established significant impact which talent acquisition has on employee performance and engagement. Similarly, Aposporia et al. [20] carried a study in Southern and Northern Europe on human resource management and organizational performance and revealed a positive association between talent acquisition and organizational performance. Thus leading us to assume talent management will positively influence health workforce engagement within Human Resources for Health(HRH) Systems Strengthening interventions.

One of the greatest challenges for organization is to maintain and satisfy their talented and high performing employees [21]. In order to retain talent in organizations, there must be programmes on motivation, training, performance assessment, career progression and compensation [7]. Becker et al. [22] suggested that "a compensation package that clearly stipulates expectations of performance, skill requirements, experience, and behaviour" is a prerequisite human resource function if organizations are to succeed. In order to record high performance and workforce engagement, there is more to be done other than only compensation and reward, recruitment and retention mechanisms, as the only pillars to support the organization performance [22]. Career progression management entails utilization of vital employee information about the employee "interests, norms, knowledge, strengths and weaknesses on skills, shaping career objectives, and integrating in career strategies that target at increasing the chances of attaining career goals" [23]. Career management entails formal and informal talent management activities, i.e. job rotation and providing practices for personal development [24]. The study by Dargham [24] on career progression concluded that there is a positive influence of career management on increasing both organizational performance and workforce engagement. Dychtwald et al. [25], additionally stressed that performance management systems in support of overall organization objectives, should be designed to cater for different perceptions of different workforce generations and the determinants of workforce retention. Similarly, the study strong believes career management practices if carefully designed would greatly improve public health service delivery, but such an assumption need to be proved.

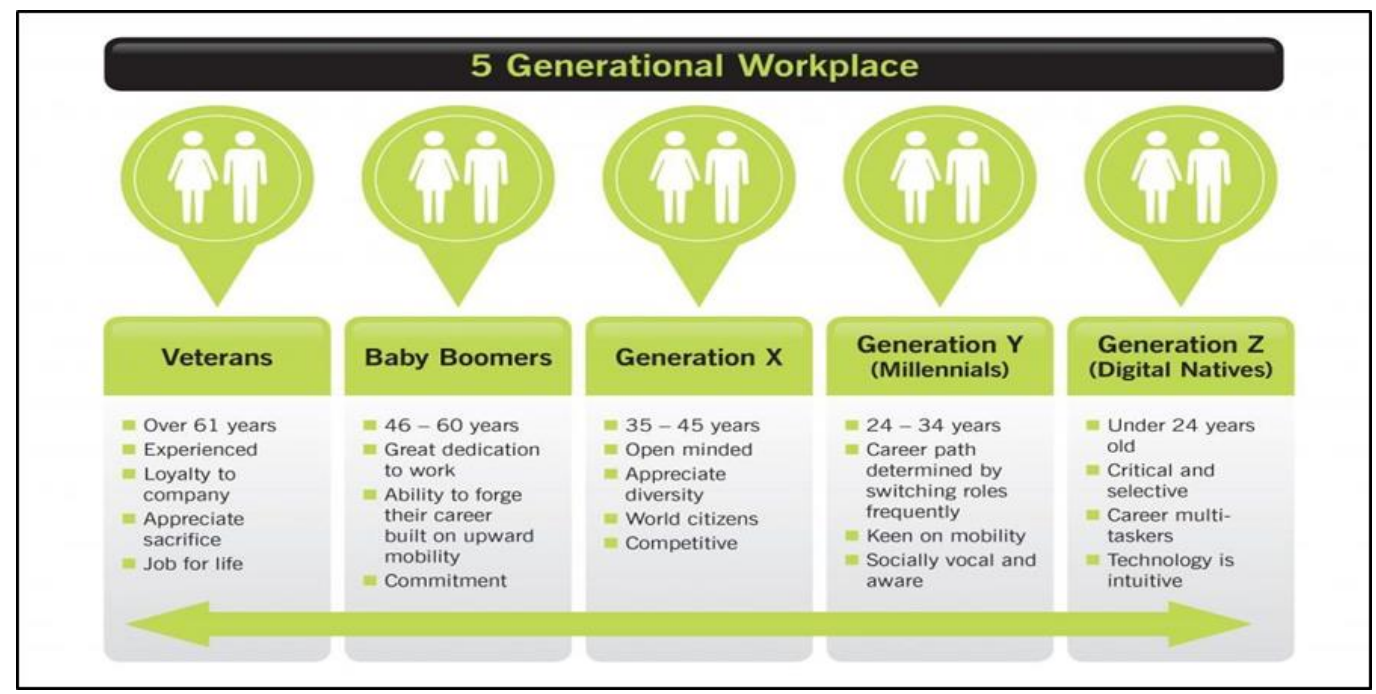

Figure 1 The Workforce Generations

Source: Adopted from Baker Tilly Mooney Moore

https://www.google.com/url?sa=i\&url=https\%3A\%2F\%2Fwww.bakertillymooneymoore.co.uk 
There are generally four generic workforce generations that exists today, and it is the role of human resources function to understand types of talents that make up these groups in order to realise full engagement and productive performance. The characteristics of each generation group i.e. age is more likely to have a strong relationship with performance and engagement. The various generations that exists in the health workforce today is outlined in Figure 1;

Generally, 'Boomers' are viewed as workaholics who enjoy working long hours and are prepared to work overtime thus perceived to be more committed to their work roles compared to all other generations. The Baby boomers' generation are reflected as team players, captivated in retirement age, with a fondness for structure and discipline but however, less persuaded to easily accept change. They need more authority and to exercise control not necessarily skills and talent development. By nature, 'Baby Boomers' are competitive, hence human resources strategies need to be mindful of their peculiar need for recognition and rewards to keep them motivated and engaged. The generation of 'Millennials' referred to as 'Generation Y', constitute workforce born between 1980 and 2001, who when they are appointed into service, come in with a lot of different expectations [26]. There is a strong perception that Millennials are not engaged as they want to operate in an independent manner, relying largely on the use of technology in work circlers. Millennials by their nature are experimental hence they need to be left alone to create their own processes rather than being dictated on what to do all the time. Research proved the Millennials lack strong work ethic, with the mainstream expected to work an average of 38.8 hours in a week compared to other generations who on average work above 40 hours in a week [27]. This generation is easily irritated regarding career progression, about 49 per cent are likely to leave the organization within two years of service if they feel their skills and talent are not being fully utilized [28]. While Boomers commonly assume they may spend one to five years in a particular position before being promoted, Generation Y are eager to know where they are going to be in the next month [25]. Phillips and Roper [26] pointed that it is essential for organizations to be creative when developing a human resources recruitment strategy and in cognisance of generation characteristics, avoid the traditional methods of recruiting and managing talent, especially when targeting to attract 'Generation Y' [26].

The 'Generation X' group are known as being content with their work and favour work environment such that they do not easily complain. By virtue of the long service over years, the group developed to become engaged. A number of organizations, about 70 per cent, have been converted to believe Generation X are the best overall workers [29]. The Gen X consists of committed professionals trying to balance both work and family time hence they always prefer worklife balance. However, research proves amongst the Generation X group, less than 40 per cent are satisfied with the senior management authority in an organisation proving that they are not easily manageable. They are bound to disagree with management compared to other successive generations. In term of performance, the generation is understood as able to do things quickly and are not motivated to more spend hours (overtime) completing work tasks to perfection. In each and every generation, there is something uniquely valuable about the workforce such that human resources system strengthening initiatives need to blend modern talent management practices so as to realise desired health outcomes.

Generally, published literature on talent management exhibits lack of evidence and empirical studies [6]. Past researches have underlined the significant association between talent management and organizational performance $[17,30,31]$, however what remains unexplained is how the talent management practices can be deployed for attainment of highly engaged workforce leading to improved performance realised. Further, existing literature indicate research on talent management practices have been conducted in developed countries especially in Europe, where the concept is perceived as mature. However, in most developing countries, organizations have recently adopted talent management strategies with the view of achieving similar results to those in developed worlds. This will not be true as there remain variables (such as culture, gender profile, age of workforce, structural imbalances), which will affect differently the implementation, level of employee engagement and overall performance [32, 33]. Although numerous research on talent management practices was carried out in both developed and developing countries [31, 34], little if none was done on service delivery settings especially health care industry. CEL \& Associates a management consulting firm, concluded there is a talent crisis in the real estate industry emanating from a weak platform for talent retention and ineffective human resources strategies, including compensation and management of performance and career progression [26]. Therefore, the aim of the study is to review talent management practices in the public sector, the effectiveness of talent management practices in stimulating increased engagement, improved performance and realisation of objectives of public health systems in low resource settings. The findings of this study will give a basis for prioritisation of human resources interventions as part of the health systems initiatives for the public health sector. 


\section{Material and methods}

\subsection{Design, study population and sample}

A cross sectional study was carried out using a survey amongst the health professionals employed on pensionable conditions of service at Parirenyatwa Group of Hospitals, at least three years prior to the survey. In achieving research objectives, the study was two pronged. Firstly, an in-depth assessment of the relevancy and effectiveness of talent management practices relied on responses from a sample of $n=200$ comprised of head of various departments, supervisors and human resources practitioners at Parirenyatwa Group of Hospital. The selection of the subjects was based on the role played by the management teams in identifying and utilization of health workforce talent that promotes employee engagement essential for performance of the public health system. Purposive (non-probability) sampling technique guided in identifying $n=200$ health management cadres to assess the perception of implemented talent management approaches. The use of Parirenyatwa Group of Hospital became the target given the fact that it is the country's major public referral health institution with the biggest patient bed capacity hence it is a typical health system ideally supported by effective utilization of health workforce talent. The impact of talent management practices would be reflected where there is dynamic skill utilization driven by effective Human Resources for Health interventions.

The study further utilized a population of $(\mathrm{N})=700$ randomly selected health professionals that were on pensionable conditions of service to analyse determinates of effective health workforce engagement from utilized talent management practices. It is from the population, that a sample of $n=450$ mixed health workers appointed in the last 3 years prior to the survey, was calculated based on the proportional departmental (N) population size with degree of confidence of $90 \%$ (alpha error of 0.1 ).

Table 1 Population and Sample Sizes: Workforce engagement.

\begin{tabular}{|l|l|l|l|}
\hline Managerial level & Population (N) & Sample (n) & \% of sample to population \\
\hline Frontline workers & 455 & 285 & 63 \\
\hline First line managers & 155 & 95 & 61 \\
\hline Middle managers & 85 & 66 & 78 \\
\hline Senior managers & 5 & 4 & 80 \\
\hline Total & 700 & 450 & \\
\hline
\end{tabular}

The Sample of $n=450$ health professionals was put on regression to analyse the probability association between the explanatory variables picked from talent management practices utilized at hospital namely; recruitment and selection, compensation and rewarding, succession management, performance management system and the age of health workforce to employee engagement. The study dependent variable was health workforce engagement by those employed on pensionable conditions of service in the last 3 years using binary response yes/no. In selecting respondents, primary sampling units were first randomly selected from the major clinical departments of the institution and thereafter subjects were considered on probability proportional to size. All sample elements were randomly selected and calculated in view of number of health professionals utilizing various talents in departments.

\subsection{Data collection and analysis}

The research used a data collection tool designed and guided by different talent management models the Collings and Mellahi model and the Develop-Deploy- Connect model aimed at improving organizational performance and employee engagement Error! Reference source not found. to assess the perceptions on utilized talent management practices and the relationships between talent management themes to health workforce engagement. The underlining assumption was that highly engaged health workforce would emanate from clear understanding of talent management role as part of health systems strengthening initiative. The applicability and clarity of questioning in the tool was improved after pre-testing with the expertise from health system strengthening specialists working with the Ministry of Health and Child Care in the country in order to attain possible data relevancy, reliability and accuracy. The data collection tool covered mainly the employee progression profile and the talent management practices soliciting for binary responses on identification and utilization of talent vis-a- vi-s health workforce engagement. Data collectors were used to self-administer the research data instrument following the preliminary training on research focus and data 
collection ethics. The preliminary data collection training clarified on the study variables, data legitimacy in collection, safeguarding respondent's confidentiality, and treating professional opinions Error! Reference source not found..

The study also used face-to-face interview schedule and organisational documents to understand talent management practices applied in public health institutions. Collections of documents reviewed included the recruitment policies, human resources strategic plans, on-boarding manual, performance management and retention framework. Clarification on responses on institutional health systems strengthening programs was sought from the Human resource office as custodians of talent management practices. In ensuring data quality and consistency, pre-testing of the data collection tool was done and adjustments were made prior to the actual survey. Summaries of the descriptive data and cross tabulations were compiled to draw meaning on the relevancy and effectiveness of talent management practices in influencing health workforce engagement within a public health system. The logistic regression analysis based on $64 \%$ of the response rate, and significance level at $<0.05$, ascertained the association between study variables to determine health workforce engagement. A univariate analysis was performed to describe the distribution of the outcome variable and explanatory variables using the chi-square test for categorical variables. The Statistical Package for Social Sciences (SPSS) version 2.0 was used in the data analysis.

\section{Results and discussion}

Of the respondents, the distribution indicated 33\% were females and 67\% were males. In view of the gender distribution, the common myth that scientific subjects are meant for males in a health profession Error! Reference source not found. found sense at this organisation. Of all the age groups, the $18>30$ age group has the largest number $(47.37 \%)$ which suggests millennials constitute a fairly large group of health workforce in the public health sector. The distribution may suggest human resource practitioners need to come up with more involving workplace activities to demystify the theory that millennials are generally finding it difficult to engage. The age groups $31-<40$ and $41-<50$ cumulatively add up to $43 \%$ of the respondents. These are the people who were born between 1964 and 1980 and generally defined as mature and expected to be fully engaged to their work, though with complex choices and preferences. This group is made up of the Generation X Error! Reference source not found., the equivalence of those who were born during the liberation struggle in Zimbabwe. The age group 51> and above had 10.53\% of the sampled subjects. These are the people who were born between 1946 and 1963 although not all of them are the baby boomers group. In analyzing workforce engagement amongst various age groups in the public sector, modelling was conducted and the output is outlined in the Table 2.

Table 1 Regression Results Talent Management Practices on Workforce engagement

\begin{tabular}{|l|l|l|l|l|}
\hline \multicolumn{5}{|c|}{ Dependent Variable: Health Workforce Engagement } \\
\hline \multicolumn{5}{|c|}{ Method: ML - Binary Probit (Newton-Raphson / Marquardt steps) } \\
\hline Variable & Coefficient & Std. Error & z-Statistic & Prob. \\
\hline Recruitment_Attraction & $0.1942^{* *}$ & 0.0896 & 2.1680 & 0.0593 \\
\hline Succession_Management & $0.3210^{* *}$ & 0.1475 & 2.1761 & 0.0295 \\
\hline Compensation_rewarding & -0.0085 & 0.0880 & -0.0962 & 0.9234 \\
\hline Performance Management & $-0.2469^{* * *}$ & 0.0867 & -2.8476 & 0.0044 \\
\hline Age of health workforce & $0.3728^{* * *}$ & 0.1483 & 2.5145 & 0.0119 \\
\hline C & $-1.5821^{* * *}$ & 0.4497 & -3.5183 & 0.0004 \\
\hline McFadden R-squared & 0.052425 & Mean dependent var & 0.179173 \\
\hline S.D. dependent var & 0.383791 & S.E. of regression & 0.377879 \\
\hline LR statistic & 26.04914 & Avg. log likelihood & -0.450191 \\
\hline Prob(LR statistic) & 0.000218 & & & \\
\hline Obs with Dep=0 & 536 & Total obs & & 450 \\
\hline Obs with Dep=1 & 117 & & \\
\hline
\end{tabular}


The distribution suggests the public sector succession planning strategies would need to be in place for the millennials well in time to adequately replace the considerable number of those at retiring stages. Notwithstanding that the civil service retirement age in Zimbabwe is from 55 years, equally the role of human resources is to adequately plan in managing the exit of the 'baby boomers' employees who are already fully engaged and have developed an attachment to their work by virtue of long service. In reality those that develop work, attachment over time, find it very difficult to accept that they have to retire from service.

The Logistic regression analysis revealed recruitment and attraction practices, and succession management as talent management practices, if effectively used by human resources practitioners, positively influence health workforce engagement and all were significant at 5\% level. The study revealed for a unit increase in use of recruitment practices i.e. use of external adverts in employing would result to in an increase in health workforce engagement by 0.19 . The study suggests, as human resources departments become more interested in implemented succession planning programmes especially amongst the millennials, health workforce engagement would increase by 0.32 . The results lead us to conclude that succession planning practices, if carefully practiced, becomes one of the essential contributors towards health systems strengthening for the public health sector. The results further support the theoretical assertion by Ashley Autry Error! Reference source not found. that organizations without succession plans tend to lose more employees in the age group $30-<45$ years (millennials) as they seek for organizations that recognize and fully utilize their talent. Therefore, talent management practices become essential and if carefully implemented, are likely to help public health systems retain rare skills especially in highly specialised functions.

Of the interviewed $n=200$ sample of managers, $60 \%$ of the respondents agreed that the organisation has talent pools from which to replace people at any level of the organisation. Of the interviewed, about $30 \%$ who received direct appointment to promotional posts, were once part of the public health system, they at some time resigned to join other non-governmental organisations and came back to re-join government. This information reveals that most of the managers have institutional memory hence have a reason to be engaged. Therefore, it becomes the role of human resources practitioners to ensure such talent is supported for the benefit of health service delivery. In ascertaining ownership of talent management practices, the study interview results indicated the majority of $(n=200)$ managers were well versed with the recruitment processes and policies used at the public health institution.

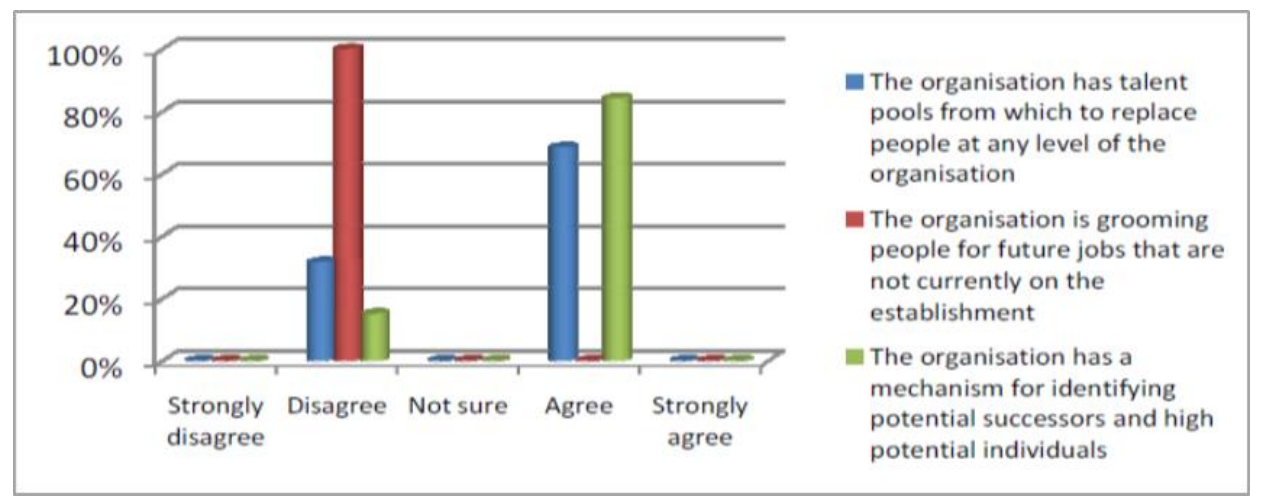

Figure 1 Distribution of Respondents on Talent management

The organization manages to recruit from both internally and external hence maximising chances of getting best talent from the market. Further, about $75 \%$ of the interviewees agreed they possess good recruitment and succession knowledge while $12 \%$ strongly disagreed. However, approximately $3 \%$ were not sure. Although the organisation has a recruitment system, research revealed its recruitment practices still lag behind and are mutually exclusive of the best practices such as recruiting online. Therefore, the study results support the claim that successful organizations are those whose human resources departments have clearly defined human resources policy framework supporting and dealing with challenges thrown up by health system reforms [40]. There is sufficient evidence pointing that attaining health system objectives, largely depends to a large extent on the provision of effective and efficient talent management practices. Therefore, there must be continuous capacity building of human resources departments to firstly own policies that influence talent management so as to ensure ultimate health workforce engagement.

The study discovered adherence to implementing performance management system in talent management for health workforce is negatively associated to employee engagement. The variable was significant at $1 \%$ level. As management teams enforce adherence to performance management system requirements in the public sector, health worker's engagement decreased (Coefficient $=0.24$ ) across all age groups, including the Generation X and Baby Boomer 
employees who by their nature are expected to be more focused and engaged by virtue of long service. The gap revealed from the model results may suggest there may be a weak human resources monitoring mechanism that fails to inculcate a positive culture of performance and practice, leading to ineffective utilization of talent. In theory, Generation $\mathrm{X}$ employees are content with their work, more paper based, thorough in work, favour work environment and they do not easily complain [41]. In verifying the model applicability, interviewed heads of sections highlighted that although they may feel undervalued at Parirenyatwa Group of Hospitals, they are not prepared to change their career paths. The analysis was further made more complex when responses from $n=200$ managers interviewed revealed there is a sound performance management system that is monitored (about 80\%) and employee's performance is tied to organizational goals performance management (about 99\%). However, the role of performance management system must be equally elevated within health system initiatives in order to achieve ultimate health workforce engagement. The applicability of the Performance management system needs to be moved away from the traditional approach and adopt contemporary methods that will suit the various workforce generations dominating the public health sector.

In the model, compensation and rewarding practices in a public health set up proved an insignificant variable to health workforce engagement ( $p$ value $=0.92$ ). Although the variable is insignificant, issues of compensation and rewarding remain central for human resources departments and theoretically are perceived to be linked to workforce engagement. The results from the model are contrary to other research findings conducted by [22], where compensation and benefits had a strong positive association to employee performance. About $80 \%$ of respondents further indicated they were not aware of the value associated with performing well and they feel human resources departments are disinterested in their performance. At PGH there is no practice of internal rewards other than the salary and wages offered by the employer hence health workers have a reason to be disengaged. Wiersma, [42] claim intrinsic rewards play a central role in keeping employees attached to the organization at the same time the higher they are compensated and rewarded, there is high probability of being engaged. In future, this claim need to be tried and tested its applicability but using specific elements as proposed by different scholars.

Of the $n=450$ respondents, about $48 \%$ had stayed at the organisation from five to twenty years, only $15 \%$ had served in excess of fifteen years indicating the majority of health workers studied fall within millennials and the Generation $\mathrm{X}$ groups. The results could enrich health workforce planning especially understanding the distribution across various health care functions. The regression results revealed as the age increases, the health workforce become more engaged and self-motivated to develop their personal talent (significant at 5\% level), thus theory suggests such are 'Baby Boomers' age group who are prepared to perfect their work talent for the benefit of the health system. For every unit increase in the age of an employee, the probability of attaining health worker engagement would also increase by 0.37 . The research findings are proving wrong the disengagement theory of aging quoted by P M Burbank [43,44] claiming it is expected and acceptable for adults to withdraw from formal work commitments, society and personal relationships as they grow older in age. The model results also support the Generation $\mathrm{X}$ theory in the public sector settings which purports that such (Generation X) group favour work environment, don't complain thus are engaged by virtue of long service. Therefore, age comes out an important variable to be considered in systems strengthening for human resources for health. Careful profiling of employees ought to be done routinely in human resources management in order to identify 'dissatisfier' elements amongst various health workforce age groups in an organization. In a long term focus, public sector human resources for health interventions should strive to synchronise the strategic plan with the talent management strategy in order to support achievement of desired health outcomes [45].

\section{Conclusion}

Attaining health objectives for public health systems largely depends on highly engaged health workforce. It is the role of human resources office to gather sufficient information about workforce characteristic i.e. age, skill in order to build vibrant talent management practices that will support the provision of efficient, effective and high-quality health services across different geographical regions. The lack of explicit talent management policies and programmes in health systems strengthening, in most public sector settings, poses imbalances that threaten the ability of health care systems to achieve their desired objectives. The health workforce has specific performance features that cannot be ignored in planning for improved service delivery. Thus ensuring engaged workforce appears to be a crucial part of the health policy and talent development process carefully designed to cater for varying features of the existing workforce. Although compensation and benefits contribute towards retaining workforce at work, there are other essential variables (i.e. designing performance management framework, responsive and relevant recruitment strategy, availability of a clear career progression path) to be considered when planning for improved performance. Putting workforce problems on the health systems agenda and developing explicit intervention programmes need to follow a systematic approach offered within an integrated human resources network. In the long term, such efforts unlock the prospect of building vibrant public health care systems that are more responsive to the health needs of the populations. 


\section{Compliance with ethical standards}

\section{Disclosure of conflict of interest}

The authors declare that they have no competing interests.

\section{Statement of informed consent}

Research clearance and authorization was obtained from the leadership of Health institution studied. All interviewees participated on a voluntary basis, after signing an informed consent form. The right to refuse to participate or withdraw from the survey, anonymity and confidentiality were guaranteed, as was data protection. The data remained anonymous. No ethical issues arose during the study, as all the data remained anonymous with no identifying personal data.

\section{References}

[1] Gilles Dussault, Carl-Ardy Dubois. Human resources for health policies: a critical component in health policies. Human Resources for Health; BioMed Central Ltd. 2003; 1 : 1.

[2] Dries N. Talent management, from phenomenon to theory: Introduction to the Special Issue. Hum. Resour. Manag. Rev. 2013; 23: 267-271.

[3] Prarthana Ghosh. What is Talent Management? Definition, Strategy, Process and Models. 2009.

[4] Prachi Juneja; Management Study Guide; What is Management?. 2010

[5] Cheese P, Thomas RJ, Craig E. The Talent Powered Organization: Strategies for Globalization, Talent Management and High Performance; Kogan Page: New York, NY, USA. 2007.

[6] Thunnissen M, Boselie P, Fruytie, B. A Review of Talent Management: Infancy or Adolescence? Int. J. Hum. Resour. Manag. 2013; 24: 1744-1761.

[7] Devi S. Impact of Talent Management on Organizational Performance: Role of Employee Engagement. Int. J. Manag. Stud. 2017; 4: 2231-2528.

[8] Behera MK. Talent Management: Still a Clandestine. Int. J. Bus. Manag. 2016; 4: 271-276.

[9] Carole Tansley, The currency of Talent management: A reply to "talent management and the relevance of context: Towards a pluralistic approach" Human Resource Management Review. 2013; 23(4): 337-340.

[10] Paauwe J. HRM and Performance. In Search of Balance; Tilburg University: Tilburg, The Netherlands. 2007.

[11] Rop L. Influence of Talent Attraction on Organizational Performance in Public University Campuses in County Government of Nakuru, Kenya. Int. J. Manag. Inf. Technol. 2015; 10: 2453-2460.

[12] Nikravan L. How to Keep High-Potential Employees. 2011.

[13] Dunford BB, Snell SA, Wright PM. Human Resources and the Resource Based View of the Firm (CAHRS Working Paper \#01-03); Center for Advanced Human Resource Studies, School of Industrial and Labour Relations, Cornell University: Ithaca, NY, USA. 2001.

[14] Filmer S. Talent-Retention Six Technology Enabled Best Practices. 2012.

[15] Agarwal P. Fitting Talent Management Strategy into National Culture. Indian Inst. Manag. 2016; 2: 1-11.

[16] ELMO Cloud HR and Payroll 7 Benefits of Having a Talent Management System. 2016.

[17] Farndale E, Kelliher C, Hope-Hailey V. Work and organisation engagement: Aligning research and practice. Emerald J. Organ. Eff. People Perform. 2014; 1: 157-176.

[18] Rastgoo P. The Relationship of Talent Management and Organizational Development with Job Motivation of Employees. Acta Univ. Agric. Silvic. Mendel. Brun. 2016; 64: 653-662.

[19] Moghtadaie L, Taji M. Study of the Performance of Faculty Members According to Talent Management Approach in Higher Education. Educ. Res. Rev. 2016; 11: 781-790.

[20] Apospori E, Nikandrou I, Brewster C, Papalexandris N. HRM and organizational performance in northern and southern Europe. Int. J. Hum. Resour. Manag. 2008; 197: 1187-1207. 
[21] Mohammad A. The Impact of Talent Management on Employee Engagement, Retention and Value Addition in Achieving Organizational Performance. Int. J. Core Eng. Manag. 2015; 1: 142-152.

[22] Becker BE, Huselid MA, Ulrich D. The HR Scorecard; Harvard Business School Press: Boston, MA, USA. 2001.

[23] Greenhaus JG, Callanan GA, Godshalk VM. Career Management, 3rd ed.; The Dryden Press: New York, NY, USA. 2000.

[24] Dargham NAS. The Organizational Career Management and Career Behaviour. 2013.

[25] Dychtwald K, Erickson TJ, Morison R. Workforce Crisis: How to Beat the Coming Shortage of Skills and Talent; Harvard Business School Press: Boston, MA, USA. 2006.

[26] Phillips DR, Roper KO. A framework for talent management in real estate. J. Corp. Real Estate. 2009 ; $11:$ 7-16.

[27] Kontoghiorghes C, Frangou K. The association between talent retention, antecedent factors, and consequent organizational performance. Sam Adv. Manag. J. 2009; 74: 29.

[28] Cappelli P. Talent on Demand; Harvard Business School Publishing: Boston, MA, USA. 2008.

[29] Harber Jeffery G. Generations in the Workplace: Similarities and Differences. Electronic Theses and Dissertations. $2011 ; 1255$.

[30] Collings DG, Mellahi K. Commentary on: Talent -Innate or acquired? Theoretical considerations and their implications for talent management. Hum. Resour. Manag. Rev. 2013; 23: 322-325.

[31] Stahl KG, Björkman I, Farndale E, Morris SS, Paauwe J, Stiles P, Trevor J, Wright MP. Global Talent Management: How Leading Multinationals Build and Sustain Their Talent Pipeline. 2007.

[32] Castellano, S. Shifting Leadership Capability. Association for Talent Development. 2012.

[33] Gandhok T, Smith R. Rethinking Cross-Border Talent Management: The Emerging Markets Perspective. Asian Manag. Insights. 2014; 1: 18-25.

[34] Bergmann C. Talent Management. A Comparison of Industry Specific Policies and the Use of Social Media. 2016.

[35] David G. Collings, Kamel Mellahi. Strategic Talent Management: A review and research agenda. Human Resource Management Review. 2009; 19(4): 304-313.

[36] Campbell M. Smith, R. High-Potential Talent: A View from Inside the Leadership Pipeline. Center for Creative Leadership. 2014.

[37] Annaliese K. Beery and Irving Zucke. Sex Bias in Neuroscience and Biomedical Research: Neurosci Biobehav Rev. 2011.

[38] Misti Burmeister. 'From Boomers to Bloggers': Success Strategies Across Generations Paperback, Synergy Press. 2008.

[39] Ashley Autry. Employee Engagement \& Loyalty Statistics: The Ultimate Collection, Access Perks. 2019.

[40] Gilles Dussault; Carl-Ardy Dubois. Human resources for health policies: A critical component in health policies. Hum Resour for Health. May 2003; 1(1): 1.

[41] Jeffery G Harber. Generations in the Workplace: Similarities and Differences, East Tennessee State University. 2011.

[42] Uco Jillert Wiersma. The effects of extrinsic rewards in intrinsic motivation: A meta-analysis, J. Occup and Org Psych. 1992; 65(2): 101-114.

[43] Burbank PM. Psychosocial theories of aging: a critical evaluation, ANS Adv Nurs Sci. Oct 1986; 9(1): 73-86.

[44] Schroots JJ. Theoretical developments in the psychology of aging, Gerontologist. Dec 1996; 36(6): $742-8$.

[45] Barney JB, Wright PM. On Becoming a Strategic Partner: The Role of Human Resources in Gaining Competitive Advantage. Human Resource Management. 1997; 37: 31-46. 